\title{
New Governance in the European Union: Omc
}

\author{
Ylber Aliu \\ Public Administration Faculty, \\ $A A B$ College, Kosovo
}

DOI: https://doi.org/10.36941/mjss-2022-0oo3

\begin{abstract}
The main purpose of this paper is to study the new governance in the European Union: the open method of coordination (hereinafter: $O M C$ ). Some of the main features of the OMC are: an instrument of spreading the best practices of achieving the EU's main goals; to help member states develop their policies; creating a calendar for achieving project goals: short, medium and long term; translating European guidelines into national and regional policies specifying objectives and measures; as well as periodic monitoring and evaluation. The main value of the OMC is all involvement in decision-making: European Union institutions, civil society, interest groups, media, etc., through the OMC play a role in the process of drafting public policies and monitoring and evaluating implementation. The OMC aims to complement the 'democratic deficit' of EU institutions, especially in the education policy, employment policies and social welfare policies. We have used two methods for research of the paper. The first, the method of research of scientific and academic literature related to the European Union. Second, the case study of individual cases for displaying the new governance format: OMC in the European Union. The result of the research is to understand what new governance in the European Union is, when it comes to expression of this form of governance, who are the main actors in implementing new governance, when it has started to apply, etc. The conclusion of the paper is that the new governance in the European Union: the OMC has transformed the decision-making process as well as the process of drafting policies, strategies and legislation within the EU.
\end{abstract}

Key words: open method of coordination, European Union, governance, research, integration

\section{Introduction}

New governance in the European Union: the OMC has transformed the process of decision-making and drafting legislation within the EU. For the purpose of carrying out this study, we have conceived the research work in several parts. In the first part, we will analyze the context of European integration, focusing on the concept of integration, in the context of European integration. Then in the analysis of the rationality of European integrations, to its own analysis of the European Union (hereinafter: EU), respectively supranational and inter-national elements. In the second part, we will analyze the concept of new governance in the EU by elaborating the definition of this concept, the policy sectors when implemented this method, the main features and dimensions of the open method of coordination and other relevant elements with this new government.

Two sets of methods are used in the paper. First, methods for collecting data. Data is collected from academic and scientific literature related to the EU. Also, another part of the data was obtained 
from the Internet, such as: publications, reports and analyzes referring to the new EU governance. Second, the methods for the logical structuring of the collected material in advance. In the group of these methods, there are the classical methods of social sciences such as: analysis - study of matter from the general to the constituent parts, synthesis - study of matter from the straight parts to the general, complete induction (with all constituent cases of matter) and incomplete (Matthews, B. dhe Ross, L. 2012; Eco, U. 1997; Manheim, J. B. 2002; and, Feraj, H. 2004).

\section{European Integration Context}

In the framework of the context of European integration we will analyze the concept of integration in general as well as some ideas regarding the reasonableness of European integrations.

There are different opinions in the literature regarding the concept of integration and European integration. Thus, integration between states, according the Goldstein (2003), is understood as "... a process that has to do with the process between which international institutions begin to replace national ones, with the slower movement with a high degree of sovereignty from state to regional or world structures" (p. 414). Then, such a change of sovereignty at a national level would probably bring about a variant of federalism in which states (or other political units) would accept the sovereignty of a single central government, while retaining some power for themselves (Ibid). While, according to Dojc (1994), integration means the connection of two or more independent and sovereign states in institutional form. In this sense, the notion of integration is more contextualized in terms of politics, giving the substantial elements that build integration. These elements are:

1. Independent and sovereign states.

2. The link between these states.

3. The link must be in institutional form.

Also, according to another opinion, integration means peaceful and voluntary approach, union of societies, states and peoples economies, beyond the boundaries that exist so far (Wajdenfeld, W dhe Wessels, W, 2005). From this perspective integration must answer these questions:

1. Why is regional integration developing?

2. How does the establishment and expansion of regional integration come from?

3. Who are the key authors in the integration process?

4. Where will regional integration take place? (p. 398).

Each of these theories has space for critical insights. First, Goldstein's concept of integration explains integration only in the foreign policy plan, as integration between independent and sovereign states, but not in the domestic policy plan, integration within communities living within a country, whether in the political, social, linguistic, cultural, etc. sense. This is due to the fact that success (or failure) in the internal policy plan of the integration process has contributed to dictating success (or failure) in the foreign policy agenda in terms of integration, such as Spain, Britain Greater Greece, etc. Secondly, Dojc's concept explains integration into relations between two or more states linked in institutional form. Viewed from a chronological point of view, the persistence of this theory collapses. Because institutional links between sovereign and sovereign states have been seen earlier when two or more states have established alliances between themselves (the Holy Alliance), but this process is not called integration because integration does not only mean institutional links between independent states and sovereign. And instead of the concept of integration, the concept of alliance is used because integration and alliance are not identical things. Third, Wajdenfeld's concept of integration is much more in the sociological and political context. It is not necessarily said that integrations are made only by peaceful approach; many cases are argued the opposite: that integrations can also be achieved through non-peaceful means. It is in the nature of phenomena in general, and especially in political phenomena, that the means of realizing that phenomenon does not determine the matter of the phenomenon in question.

Different scholars have elaborated different ideas on the justification of European integration. Through these ideas, it is intended to penetrate into the most general, fundamental reasons that have 
led to the beginning of European integration. The rationale for European integration refers to the need of the United States after World War II for the creation of new markets for the placing of goods that had reached the point of overproduction due to the inability to have access in the market at European. Europe's economic recovery, according Pocar (1998) would have allowed the creation of new markets to which United States exports could be directed, thus finding a way out of the situation of American industrial overproduction. While, other authors, the justification of European integration is seen from a different perspective. Thus, "Though it is thought that this was largely a European idea, the creation of a united Europe, integrated and capable of carrying forward the postwar economic and industrial development of a Europe to be re-built but also of having to forgot European traditional animosities and rivalries, and above all to oppose the bipolar partition of Europe from the Cold War, was just as American project ... The United States did not want to leave the divided Europe between the East and the West, much less distinct from the ideological iron curtain and the least with the geopolitical and geostrategic control of a part of Europe by the Union of the Soviet Social Republics. According to Dojc, the European states involved in the integration process were aiming to move in four main directions: - security, countries had failed to try to protect their peoples from the great destruction of World War II and was hoped that a Europe united would do better and protect them from a visible threat of communist expansion ... In the direction of power Europe's countries had lost many, lost their colonies, at least some of them, and had the opportunity to lose those that remained (Ibid). Also, the rationality of European integration is also seen from the internal context of the integration states. Thus, "Germany intended to reach an agreement with the French government to allow it to regain control of raw material production under the control of the ally in terms of steel and, in respect of coal, subject to an International Authority of Ruhr, founded on 28 April 1949 on the basis of a French proposal. From another point of view, France, a historically hostile state of Germany, was concerned about the German economic rebirth, and finally France seemed to be the only opportunity to demand the inevitable repression of the German economic rebirth and to unlock a political situation which risks becoming worse, given the territorial disputes between the two countries regarding the control of some border areas, and in particular Saara; all the more so that an agreement concluded by France on March 3, 1950 with the German government had not achieved the expected results of the French government (Ibid, p. 13). As far as other states are concerned, the involvement of the Governments of Belgium, the Netherlands, Luxembourg, which had already linked with France and Great Britain since 17 March 1948 a founding treaty of a military, political and economic union - Union of Western Europe - as well as the Italian government, which saw the introduction in a future European agreement of a development of its diplomatic relations and the possibility of partici - pating with the equal rights among economically most influential states in the European context (Ibid). So, summing up all these explanations, we conclude that the rationality of European integration refers to:

- The economic benefits that the integration process brings; and,

- Strengthening democracy as a form of governance and free market economy, as an alternative to the communist model of social organization.

But what is the European Union? There is a wide debate among scholars of what organization is the EU: supranational or inter-national? This debate continues and is constantly inspired by the various messages coming from Brussels either in the structure of their joint institutions or their daily programs. The inter-national elements of the European Union consist in these issues: institutional intergovernmental structure (Council and Council of Ministers of the European Union). Both of these institutions of the European Union are composed of representatives delegated by the governments of the member states and protect the interests of those states by making unanimous decisions (despite a few rare cases in the Council of Ministers when otherwise defined) are taken as criteria based on which these two institutions have listed in the group of inter-national elements. Citizenship of the European Union is counted as an inter-national element. The European Union's citizenship seems to create the impression of a supranational, even state, impression in a far-reaching analysis that this is not the case, because being a supranational organization must have citizenship and not nationality. 
Also, EU citizenship cannot lead to the passing of citizenship rights as they apply to citizenship, and it complements national citizenship but does not replace it (Wajdenfed, W, 2005, p. 396). In addition, the lack of shared myths, cultures, traditions, languages, etc., which are characteristic of the nations, are taken as national elements of the EU. So the EU does not have a common language, say one European language, which is the main characteristic of the nation - states.

But the EU also has supranational elements. Initially, the transnational institutional structure such as the European Commission and the European Parliament. Without further analysis, the supranational elements of these institutions are the fact that the members of the European Parliament and the European Commission protect the interests of the EU and not the interests of member states, and decisions in these institutions are also taken by a majority of votes (Ibid, p. 158193). Then, common EU policies such as: agricultural policy is taken as a supranational element of the EU. Thus, close to $50 \%$ of the EU budget goes to the common agricultural policy (and this policy has often exacerbated the relations between member states UK and France), to subsidize farmers most favored by France and lose Britain Great, due to the opposing commitments in agriculture. Then creation (or attempt to create) new markets for European agricultural producers, design and implementation of protectionist in this area, etc. Whereas, foreign policy is an area where national and inter-national elements coexist. The main reason is that while in relation to the Crimea crisis, the EU has managed to establish a common foreign policy, similar attitudes, in relation to Kosovo's independence now (or intervention or failure to intervene in Iraq 2003), the EU remains without a unique stand, because five member states (Romania, Slovakia, Spain, Greece and Cyprus) have not yet recognized Kosovo's independence. So, the EU is an international organization within which we face supranational and international elements.

\section{New Governance in the European Union}

The new governance in the European Union refers to the open method of coordination that has been implemented in the education policy sector and other policy sectors. This method is briefly called OMC (Open Method Coordination). In the following we will analyze this method and we will see it from all possible dimensions to be analyzed.

\section{What is the OMC?}

In the EU literature there is no formal legal definition of the open method of coordination" (Lange, B dhe Alexiadou, N, 2007) or briefly the OMC. But, there have been calls from various EU factors, such as the Committee of the Regions and the Economic and Social Committee, for a definition of OMC (Ibid). Despite the calls and efforts to make a definition regarding the OMC, never such a thing has happened. It is thought that this is due to the preservation of the flexibility of this new form of governance. However, close to being widely accepted definition of governance through open method of coordination (OMC) are the conclusions reached at the meeting of EU heads of state governments:

- The OMC is a tool for spreading best practices towards achieving the EU's main goals;

- The OMC method is designed to help member states develop their policies;

- Creating a calendar for achieving short-term, mid-term and long-term goals;

- Measuring through quantitative and qualitative mechanisms in relation to best practices in the world to adapt to different sectors;

- Translating these European guidelines into national and regional policies specifying the objectives and the adoption of measures, taking into account national and regional differences; and,

- Periodic monitoring, evaluation and group review as a process of mutual learning (Ibid).

It should be noted that at the European Council meeting in Lisbon, there has been talk in general terms about the OMC, it is not specified and defined correctly, but the need to apply this new 
form of governance in the education sector has been identified. The OMC is a new form of governance, not just an expression of the EU national element, where the public, the supranational institutions of the EU (Parliament and the European Commission, namely the Economic and Social Committee, the Committee of the Regions, etc.); but include non-public actors such as teachers, academics, civil servants working in the education sector, trade union representatives, private businesses, etc (Ibid). Thus, the OMC is a comprehensive form of governance in the sense of actors from whom it is structured and implemented.

\section{The OMC process}

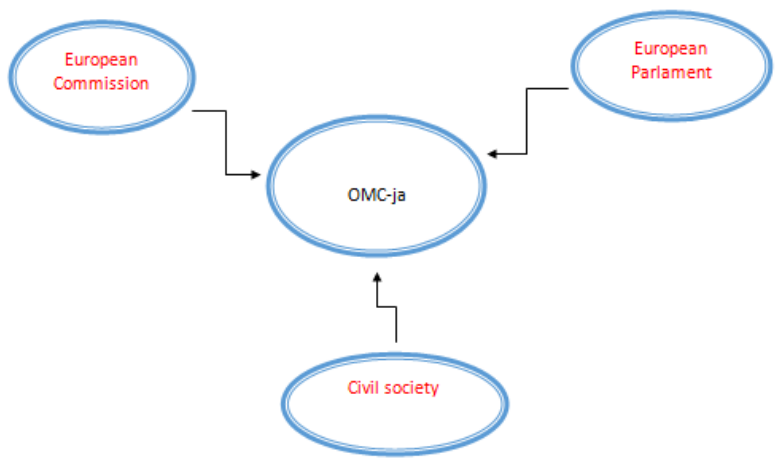

According to the authors, Armstrong and Kilpatrick, is not just an OMC, but there are some OMC-s. Depending on the type of EU policy we have the OMC. For example, the OMC has applied to: the European Employment Strategy, fiscal policies related to the pact of growth and stability, pensions, health care, social inclusion, youth policies, immigration and asylum and education policies. Viewed from this context, the OMC is a form of governance methodology. It does not include subjects in itself, but refers to the way, method and how it proceeds with the design of a public policy (public and private), or the implementation of such a policy. So the OMC is used to move from 'bottom-toback', from the most 'soft' forms to the most difficult forms. An example illustrating this aspect is the policy of social inclusion in the EU.

Although this new form of governance differs from the policy sector, it is still possible to identify some of the main, more general OMC features for all policy sectors where this method is applied:

1. Flexibility - is flexible because it relies on soft aspects; and,

2. A Reflexive Form of Governance.

The OMC is used in cases where EU institutions have limited power to develop community policies or resistance (s) from member states to EU policies. Incidentally, such are the education policies. Consequently, the OMC has developed as a new approach to addressing an old problem: 'competition' over competences between the institutions of member states and the EU institutions, between inter-national and supranational elements. Where EU institutions share competencies with member state institutions, such as education policies, employment policies and social welfare, OMCbased governance emerges, the purpose of which is to move in two directions.

1. First, member states become part of the policy-making process; and,

2. Secondly, however, this process should have a community of communion, which is the result of the involvement of EU institutions.

Otherwise, the OMC is also considered as an experimental form of governance. Some see it as a new form of government, while others criticize and dispute that it is a new form of governance. Then, the OMC criticizes whether it is really a new form of governance, or not. While, some others see the $\mathrm{OMC}$ as a form and innovative of EU governance by shifting old forms of governance. Or else, the old 
forms of governance are complemented by OMC and new forms. Or, the idea that new forms of EU governance are not entirely new because they are created in the shadow of the traditional hierarchical structures of the EU.

The basic assumption of OMC implementation is that in the EU all parties are converging towards the same objectives, proving rational and collective solutions. Although there are doubts whether learning in a political context provides rational solutions (Burkard, E dhe Kerwer, D, 2004).

New governance can transform our understanding of politics and, specifically, the law. So the new government has transformed the 'law' into the European Union. In theory, there is a lack of theories and ideas of how this transformation is taking place. It is exceptionally the model of a 'democratic experiment', which has also been applied to the European Union in a number of areas. Martti Koskenniemi described progress as a 'managerial sensitivity' to modern law. Two are the main characteristics of this sensitivity: the first, the increase in the differentiation of international rules, and the second, the tendency to look at the law not as an end in itself but as a managerial technique (Ibid).

The governance method based on the OMC is a technique for the decision-making process within the EU and the drafting of legislation (Barani, L, 2006). This author sees the method of open governance as a middle-of-the-middle process between supranational and inter-national tendencies within EU institutions. In such a context, the role of the open method of coordination is balancing: preserving the format at the supranational level, but integrating the lowest actors of the integration states into decision-making and policy-making process; thus, turning the power of EU institutions to the citizens of member states to alleviate democratic deficit.

Viewed in chronological terms, the OMC was not a much-used government method. However, this method, according Radaelli (2003), has "... penetrated slowly but steadily" (p. 5). Working groups in economic governance, simplification and complementary competencies, and above all social Europe have used this method in the realization of their platforms. The open method of coordination, according to this author, has several key features: the first, is legitimate debate, is a method or are some methods (?), The role of the OMC in problem solving, open coordination as an abstract framework: a forward alternative, endemic tension, limited results, and the method has not met all the trends in the coordination process, though something has been achieved. According to Radaelli, the debate over the OMC method takes into account three main dimensions:

- First, when and how this method should be used, viewed in this context, should it be used only in the context of education policies or in the context of other policies;

- Secondly, we need to understand the performance of different forms of governance within the same policy fields, if a form of governance is successful in the case of a policy, then it should be applied rather than uniformly, but to adopt functional forms of governance in certain policy areas; and,

- Third, at the end of the process, one should not look at how to improve OMC but how to improve EU institutions to function better. The third dimension writer 'strips' the OMC and the debate focuses on the underlying principle: that the EU is not in the function of the OMC, but the OMC in function of better governance by the EU's unitary institutions.

It is also criticized by the approach of some who go so far as to speak of "... a social market economy" (Ibid, p. 11). This aims to democratize the 'territory' of the OMC. It is based on the relationship between the open method of coordination and the legislative aspect in the EU. However, it is warned that the OMC cannot be implemented in those areas where the EU has no competence; consequently, the OMC can only be applied in those areas where the EU has competences and can issue directives. Also states open method of coordination should not use to attack EU acuic.

Thus, the creation of the OMC should be understood in the context of an economic disintegration and lack of integration in such fields as: technology and innovation. In order to avoid this, the EU has continued with measures to regulate the market and create macroeconomic stability. The establishment and use of the OMC is also related to the EU legitimacy crisis in the early 1990 os and early 2000 (Borrás, S dhe Jacobsson, K, 2004). The EU's democratic legitimacy is not about the 
European Parliament, but also issues of transparency, accountability and openness. In this context, the OMC is seen as an instrument that can alleviate the democratic deficit of EU institutions through inclusiveness, especially in the decision-making process. The main quality of this method is the flexibility to adapt to different circumstances and actors. The OMC has brought 'fresh air' within the bureaucratic structures of EU institutions.

It is also acknowledged that this method of governance, despite its shortcomings, has transformed the concept of governance into the EU.

\section{Conclusion}

Since its founding so far, the EU has faced two major challenges: first, horizontal enlargement - the accession of new member states, especially the states that have emerged from the monist system (Eastern and South Eastern European states); and, secondly, the deepening of vertical enlargement or change the extension of the competencies of the EU institutions in relation to the member states, namely the move towards expanding with the exclusive competences of the states and shared competences.

The main criticism of these two challenges is the argument that: The EU lacks democratic legitimacy. From the analysis in the first part, we realized that within the EU, respectively within the EU institutions we encounter inter-national and supranational elements. In order to overcome the problem of the democratic legitimacy of EU institutions, especially in the education policy sector, but also in other policy sectors, the need to create a new form of governance has emerged, which does not lacking democratic legitimacy, especially in decision-making processes, being inclusive with different actors from civil society and other non-institutional actors. Despite the successes of this new method of government, fierce criticisms have developed. Our opinion is similar to Radaell's opinion, which rightfully warns that the EU is not in the function of the OMC, but the OMC is in the function of the EU that the debate should not focus how to use and improve the method of the OMC but how to explore alternative methods of governance in order to improve the performance of EU institutions. Therefore, the more the EU advances in the process of raising democratic legitimacy in decisionmaking, through alternative methods and forms of governance, not necessarily just the OMC but also with the OMC, the more this governance method becomes completed.

\section{Reference}

Burkard, E dhe Kerwer, D. (2004). New Governance in the Eurpean Union: A theoriticall perspective. Volume 42. Number 1. Mủnhen: Technische Universität.

Borrás, S dhe Jacobsson, K. (2004). The open method of coordination and new governance patterns in the EU. Journal of European Public Policy.

Barani, L. (2006). Hard and Soft Law in the European Union: The Case of Social Policy and the Open Method of Coordination. Bruxelles: Université libre de Bruxelles.

Dojç, K. (1994). International Relations Analysis. Tirane.

Goldstein, J. (2003). International Relations. Tirane: Dituria.

Lange, B dhe Alexiadou, N. (2007). New Forms of European Union Governance in the Education Sector? A Preliminary Analysis of the Open Method of Coordination. European Educational Research Journal. Volume 6. Number 4. United Kingdom: Keele University.

Pocar, F. (1998). the right of European communities. Tirane.

Radaelli, C. (2003). The open method of coordination. Stockholm: EO - print AB.

Wajdenfeld, W dhe Wessels, W. (2005). Europe from A to ZH. Prishtine. 